\title{
Ossicular Integrity in Chronic Otitis Media (Mucosal Type): A Surgical Review
}

\author{
Sanjeev Mohanty ${ }^{1}$ \\ ${ }^{1}$ Department of ENT, Head \& Neck Surgery, MGM Health Care, \\ Nelson Manickam, Aminjikarai, Chennai, India
}

\begin{abstract}
Address for correspondence Sanjeev Mohanty, Department of ENT, Head \& Neck Surgery, MGM Health Care, Nelson Manickam Road, Aminjikarai, Chennai 600029, India (e-mail: drsanjeevmohanty@gmail.com).
\end{abstract}
Abstract
Keywords
- chronic otitis media
- ossiculoplasty
- autologous incus
- audiogram

Ossicular discontinuity usually cannot be determined unless an operation is performed. However, the predictive value of preoperative audiological factors in diagnosing incudal necrosis in patients with chronic otitis media (COM) - mucosal type is reasonably accurate. Ossiculoplasty was performed with autologous incus, and audiometric assessment was done to compare the hearing improvement postoperatively.

\section{Introduction}

Between $40 \%$ and $90 \%$ of tympanoplasties require middle ear ossicular chain reconstruction. ${ }^{1}$ Ossicular reconstruction was first performed in the 1950s. In cases with intact stapes but defective incus and/or malleus, type II and III tympanoplasties were the choice of ossiculoplasty according to the Wullstein classification in $1956 .{ }^{1,2}$ Ossicular discontinuity usually cannot be determined unless an operation is performed.

\section{Objective}

To determine the predictive value of preoperative audiological factors in diagnosing incudal necrosis in patients with chronic otitis media (COM)-mucosal type.

\section{Materials and Methods}

\section{Study Design}

A retrospective clinical study of 20 patients who underwent ossicular reconstruction with autologous incus over a period of 2 years was performed.

The following inclusion and exclusion criteria were used.

Inclusion criteria: Patients in the age group of 12 to 60 years diagnosed to have chronic suppurative otitis media-tubo tympanic disease quiescent stage/inactive stage (unilateral/bilateral) were included in the study. Patients with conductive hearing loss, along with good cochlear reserve and good Eustachian tube function as evidenced by diagnostic nasal endoscopy were included.
Exclusion criteria: Patients with chronic otitis mediasquamosal type, were excluded from the study. Patients with sensorineural and mixed hearing loss were also excluded from the study. Patients with congenital anomalies of the ear and systemic diseases such as diabetes mellitus and renal failure were not included. Patients who underwent revision surgeries were also excluded.

The pure-tone audiograms of the patients whose incudostapedial joint was found to be eroded on table were analyzed, and the relevance of pure-tone average (PTA) as a predictor of incudostapedial joint necrosis was assessed.

\section{Surgical Technique}

The surgeries were done under local/general anesthesia by postaural/endaural approach by a single surgeon.

The incus was removed and sculpted to a suitable size and shape to fit between the stapes head and malleus handle and to come in contact with the tympanic membrane. An acetabulum was created to accept the stapes capitulum and a notch in the short process to engage the neck of the malleus. Tympanic membrane grafting was done by the underlay technique using temporalis fascia graft. Single-stage ossicular reconstruction was performed ( - Fig. $\mathbf{1}$ ).

All patients were followed up at 1,3, and 6 months. Audiometric analysis was done preoperatively, at 3 months and at 6 months after surgery. Preoperative PTA was calculated using frequencies of 500, 1,000, and 2,000 Hz. The air-bone gaps were calculated based on the comparison of preoperative and postoperative averages of the three speech frequencies. Comparisons were made between the preoperative and
License terms Otology

\section{received}

June 13, 2019

accepted

June 17, 2019
DOI https://doi.org/

$10.1055 / \mathrm{s}-0039-1693833$

ISSN 2581-9607 
postoperative audiograms with respect to PTAs, air-bone gaps, and closure of air-bone gaps. The American Academy of Otolaryngology-Head and Neck Surgery guidelines define a postoperative $\mathrm{ABG}$ of $20 \mathrm{~dB}$ or less as a successful hearing result. ${ }^{3}$

\section{Results and Analysis}

The study comprised 11 females and 9 males. In the incus refashioning group the youngest patient was aged 17 years and the oldest patient was aged 55 years. Majority of the patients fell into the 31 to 40 years age group. The mean age was 36.65 years. Among the 20 patients, 12 patients were operated on the right side and 8 patients were operated on the left side.

The mean preoperative PTA was $52.38 \mathrm{~dB}$ HL, the minimum value being $45 \mathrm{~dB} \mathrm{HL}$ and the maximum value being $64 \mathrm{~dB}$ HL.

\section{Discussion}

In surgery for chronic otitis media, the reconstruction of the ossicular chain and successful physiological and functional results with long-term stability are still a challenge even for experienced otologists. ${ }^{4,5}$ Usually the incus is removed and interposed after it has been sculpted to a suitable size and shape. The simplicity and practicality of using autograft in ossicular reconstruction has continued to hold attention of otologists over the years. Ease of preparation and excellent biocompatibility are major advantages apart from good sound conduction. ${ }^{6}$

However, ossicular discontinuity is identified only if the discontinuity of the ossicular chain is confirmed at the time of operation. If preoperative information can be used to determine whether or not the ossicular chain is intact, the patient can be better informed and the surgeon can be better prepared before surgery. ${ }^{7}$

In this study series, the mean preoperative PTA was found to be $52.38 \mathrm{~dB}$ HL. The values ranged from $45 \mathrm{~dB} \mathrm{HL}$ to $64 \mathrm{~dB}$ HL. Complete disruption of the ossicular chain can result in a $60 \mathrm{~dB}$ hearing loss. ${ }^{8}$ In COM, malleus is found to be the most resistant ossicle, the handle of malleus being the most commonly necrosed part of the malleus. Incus is found to be the most common ossicle to get necrosed in cases of COM. The commonest defect was erosion of the lenticular process, followed by the long process. ${ }^{9}$ Kartush found erosion of long process of incus with an intact malleus handle and stapes superstructure as the most common defect. ${ }^{10}$ However, Jeng ${ }^{7}$ et al found that, perforation of the tympanic membrane with an edge adherent to the promontory occurred significantly more frequently in patients with ossicular discontinuity $(p=0.004)$ than in those with intact ossicular chains. Surprisingly, an air-bone gap was not significantly correlated with ossicular discontinuity.

\section{Conclusion}

Incus necrosis is best predicted by the presence of moderate to moderately severe hearing loss ( $45-70 \mathrm{~dB} \mathrm{HL}$ ). Knowledge of this information preoperatively can influence surgical decision making and preparedness regarding ossiculoplasty and patient consent. ${ }^{11}$

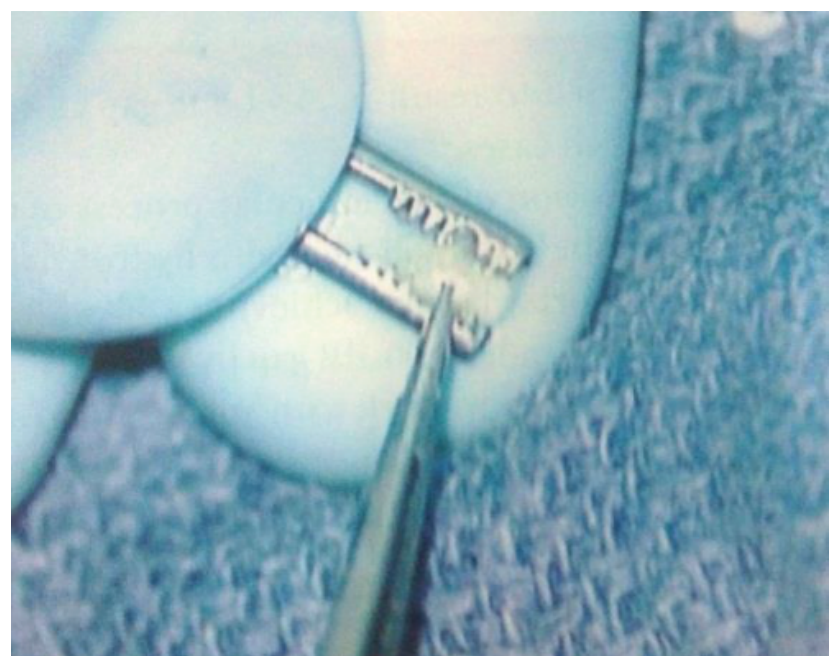

Fig. 1 Image showing the incus being refashioned.

\section{Conflict of Interest}

None declared.

\section{References}

1 Hall A, Rytzner C. Stapedectomy and autotransplantation of ossicles. Acta Otolaryngol 1957;47(4):318-324

2 Guilford FR. Repositioning of the incus. Laryngoscope 1965;75:236-241

3 Monsell M, Balkany TA, Gates GA, Goldenberg RA, Meyerhoff WL, House JW. Committee on Hearing and Equilibrium guidelines for the evaluation of results of treatment of conductive hearing loss. American Academy of Otolaryngology-Head and Neck Surgery Foundation, Inc. Otolaryngol Head Neck Surg 1995;113(3):186-187

4 Roth JA, Pandit SR, Soma M, Kertesz TR. Ossicular chain reconstruction with a titanium prosthesis. J Laryngol Otol 2009;123(10):1082-1086

5 Bast T, Anson B, The Temporal Bone and the Ear. Springfield, IL: Charles C Thomas, 1949;347

6 Chaudhary N, Anand N, Taperwal A, Rai AK. Role of autografts in the reconstruction of ossicular chain in intact canal wall procedures. Indian J. Otolaryngol Head Neck Surg 2003;55(3):157-159

7 Jeng F-C, Tsai M-H, Brown CJ. Relationship of preoperative findings and ossicular discontinuity in chronic otitis media. Otol Neurotol 2003;24(1):29-32

8 Merchant SN, Rosowski JJ, Auditory physiology. In: Glasscock ME, Gulya AJ, eds. Surgery of the Ear. 5th ed. New Delhi, Reed Elsevier India Pvt. Ltd.; 2003:70

9 Varshney S, Nangia A, Bist SS. Singh RK, Gupta N, Bhagat S. Ossicular chain status in chronic suppurative otitis media in adults. Indian J. Otolaryngol Head Neck Surg 2010;62(4):421-426

10 Kartush JM. Ossicular chain reconstruction. Capitulum to malleus. Otolaryngol Clin North Am 1994;27(4):689-715

11 Ebenezer J, Rupa V. Preoperative predictors of incudal necrosis in chronic suppurative otitis media. Otolaryngol Head Neck Surg 2010;142(3):415-420 